\title{
Термобарометрия мафических ксенолитов в трондьемитах района р. Лотта Центральной зоны Лапландского гранулитового комплекса
}

\author{
(С2021 В. Г. Бутвина ${ }^{凶}$, М. А. Голунова, О. Г. Сафонов \\ Институт экспериментальной минералогии им. Д.С. Коржсинского (ИЭМ РАН), \\ ул. Академика Осипьяна, 4, 142432, Черноголовка, Московская область, Российская Федерация
}

\begin{abstract}
Аннотация
Введение: На основе полученных ранее результатов петролого-минералогических исследований ксенолитов гранатсодержащих трондьемитов центральной части Лапландского гранулитового комплекса из района р. Лотта проведено моделирование их минеральных ассоциаций с помощью метода псевдосечений.

Методика: Расчеты Р-Т параметров и флюидного режима метаморфизма проведены с использованием хорошо зарекомендовавших себя программных комплексов GEOPATH, TWQ, PERPLEX, основанных на взаимосогласованных базах термодинамических данных. Составы минералов определялись на электронном микроскопе CamScan MV2300 (VEGA TS 5130MM) с энергодисперсионным микроанализатором Link INCA Energy. Флюидные включения в метаморфических породах были изучены в пластинках толщиной 200-300 мкм с двусторонней полировкой на установке Linkam c рабочим температурным интервалом от $-196^{\circ} \mathrm{C}$ до $600^{\circ} \mathrm{C}$ (THMSG 600) и автоматическим режимом нагревания и охлаждения образца со скоростью от 0.1 до $90 \%$ мин.

Результаты и обсуждения: 1. Моделирование минеральных ассоциаций ксенолитов методом псевдосечений и термобарометрия: Рассчитанные Р-Т псевдосечения в интервале 5-9 кбар и 600-800 представляют простые диаграммы, в которых резко доминирующим является поле ассоциации $\mathrm{Opx}+\mathrm{Cpx}+\mathrm{P} 1+\mathrm{Qz}+\mathrm{Ilm}$. С помощью программного комплекса winTWQ_2.32 рассчитаны температуры по равновесию Срх +Орх для 59 пар минералов. Для моделирования процесса амфиболизации использовалось амфибол-плагиоклазовое равновесие, которое зафиксировало температуры амфиболизации ксенолитов $740-780^{\circ} \mathrm{C}$ при давлении 5.0-5.5 кбар. 2. Флюидные включения: Флюидные включения были изучены в кварце и представлены углекислотными и водно-солевыми разностями. Bbl6odbl: Амфиболизация ксенолитов связана с проникновением в них существенно водного флюида из остывающей трондьемитовой магмы, что подтверждается резким преобладанием водно-солевых (17-20 мас. \% NaCl эквивалента) и подчиненным количеством углекислых включений в минералах гранитоидов. Несмотря на активное флюидное взаимодействие расплава и ксенолитов, признаков термального воздействия не установлено.
\end{abstract}

Ключевые слова: Лапландский гранулитовый комплекс (ЛГК), трондьемит, гранулит, основные ксенолиты, Р-Т параметры, флюидные включения, амфиболизация.

Источник финансирования: Работа выполнена в рамках темы АААА-А1 8-118020590148-3 государственного задания ИЭМ РАН на 2021.

Для цитирования: Бутвина В. Г., Голунова М. А., Сафонов О. Г. Термобарометрия мафических ксенолитов в трондьемитах района р. Лотта Центральной зоны Лапландского гранулитового комплекса // Вестник Воронежского государственного университета. Серия: Геология. 2021. №2. С. 41-51. DOI: https://doi.org/10.17308/geology.2021.2/3487

Контент доступен под лицензией Creative Commons Attribution 4.0 License.

\footnotetext{
Бутвина Валентина Григорьевна, e-mail: butvina@iem.ac.ru
} 


\section{Введение}

Геологическое строение северо-восточной части Лапландского гранулитового комплекса (далее ЛГК) довольно хорошо изучено [1-4]. Ортопироксени гранатсодержащие тоналиты и трондьемиты ЛГК образуют обширные поля в районе р. Лотта и Ловнаозера и далее на запад к северной Норвегии. Крупные интрузии гранатсодержащих чарнокит-эндербитов известны также в Колвица-Умбинском блоке, который является юго-восточным продолжением ЛГК [5]. Гранатсодержащие гранитоиды обычно приурочены к зонам развития кислых гранулитов и высокоглиноземистых пород ЛГК (кондалитов), образуя с ними либо интрузивные контакты, либо постепенные переходы. Основываясь на близости химического и минерального состава гранатовых ТТГ и вмещающих их кондалитов, ряд авторов рассматривает первые в качестве крупнозернистых разновидностей последних [6]. Однако подавляющее большинство исследователей связывают происхождение гранатсодержащих гранитоидов ЛГК с анатексисом кондалитов и кислых гранулитов на пике метаморфизма [1-4]. На это указывают геохимические особенности пород, несущие признаки типичных гранитоидов S-типа [4]. На магматическую природу гранатсодержащих гранитоидов ЛГК указывают находки в них разнообразных ксенолитов: гранат-биотитовых гнейсов, гиперстен (士гранат)-плагиоклазовых (диоритовых) и двупироксен-плагиоклазовых (норитовых, габбро-норитовых) пород [1-4]. Эти породы, по-видимому, являются продуктами более ранних стадий метаморфизма в ЛГК в условиях верхов амфиболитовой и низов гранулитовой ступеней $\left(630-730^{\circ} \mathrm{C}\right.$ и 4.0-5.7 кбар), а также продуктами кристаллизации габбро-норитовых магм в период времени 1.97-1.96 млрд лет [4].

$\mathrm{U}-\mathrm{Pb}$ возраст кристаллизации циркона 1.91 млрд лет из гранатсодержащих гранитоидов совпадает с возрастом пика гранулитового метаморфизма в ЛГК [35], что указывает на синметаморфическое образование гранитных магм. Термобарометрические данные для гранатсодержащих гранитоидов немногочисленны. На основе гранат-биотитового равновесия для гранатсодержащих трондьемитов района р. Лотта были оценены температуры метаморфизма, варьирующие от 830 до $650^{\circ} \mathrm{C}$ [2], что, безусловно, нельзя считать удовлетворительным результатом. Верхний предел этого интервала температур соответствует температурам $800-850^{\circ} \mathrm{C}$, рассчитанным по содержанию Ті в цирконе [4]. Эти температуры совпадают с параметрами метаморфизма, оцененными для пород ЛГК для 1.91 млрд лет. Они отражают условия частичного плавления кондалитов с образованием гранитной магмы на глубинах 20-29 км (6.8-9.5 кбар). Исследования флюидного режима кристаллизации гранатсодержащих гранитоидов ЛГК пока не проводились.

На основе полученных ранее результатов петролого-минералогических исследований [7] ксенолитов гранатсодержащих трондьемитов центральной части ЛГК (рис. 1) из района р. Лотта нами проведено моделирование их минеральных ассоциаций с помощью метода псевдосечений. Минеральные ассоциации ксенолитов, вероятно, отражают процессы взаимодействия основных пород с гранитными магмами и особенности флюидного режима кристаллизации этих магм. Выполнены расчеты Р-Т параметров и флюидных условий равновесий минеральных ассоциаций с использованием хорошо зарекомендовавших себя программных комплексов GEOPATH, TWQ, PERPLEX.

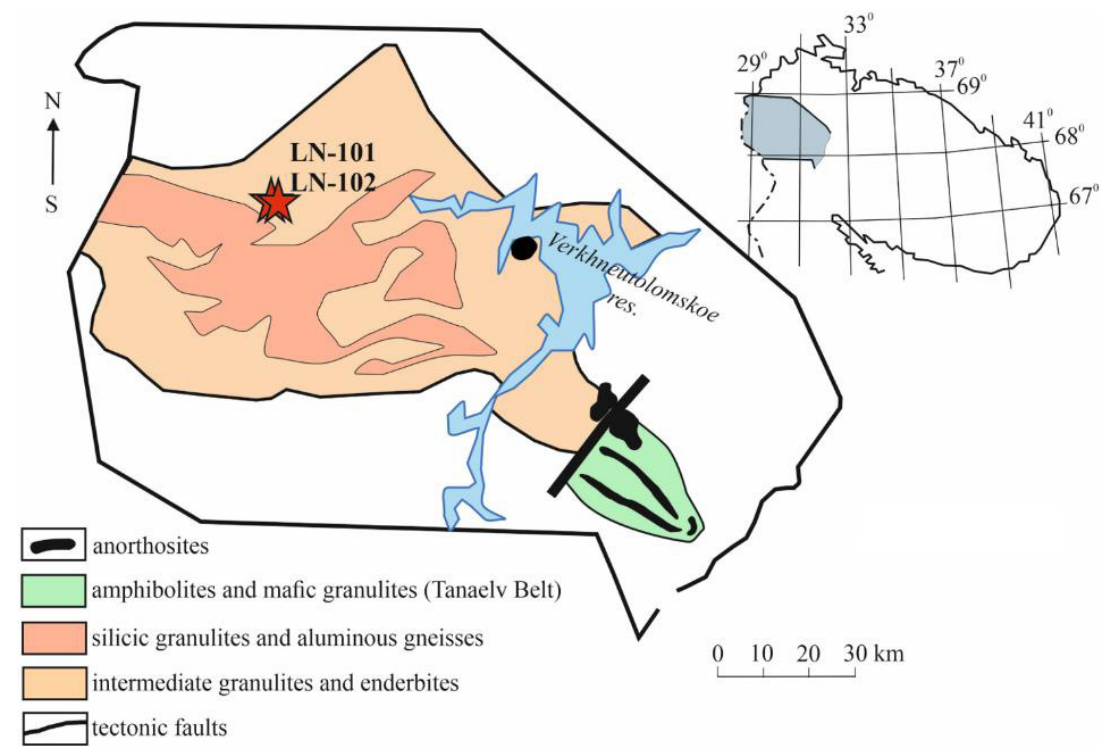

Рис. 1. Упрощенная схематическая геологическая карта Лапландского гранулитового пояса с местами отбора проб (модификация карты из [4]).

[Fig. 1. Simplified schematic geological map of the Lapland Granulite Belt, with sampling sites (modified from [4]).]

\section{Методы исследований}

Составы минералов определялись на электронном микроскопе CamScan MV2300 (VEGA TS 5130MM) с энергодисперсионным микроанализатором Link INCA
Energy, в ИЭМ РАН. Флюидные включения в метаморфических породах были изучены в пластинках толщиной 200-300 мкм с двусторонней полировкой на установке Linkam с рабочим температурным интервалом 
от $-196^{\circ} \mathrm{C}$ до $600^{\circ} \mathrm{C}$ (THMSG 600) и автоматическим режимом нагревания и охлаждения образца со скоростью от 0.1 до 90\%/мин. Стандартная аппаратурная ошибка измерений соответствовала $\pm 0.1^{\circ} \mathrm{C}$. Для расчета плотности и мольных объемов флюидных включений использовалась программа FLUIDS [8]. Изохоры рассчитывались по программе [9]. Все приборы оснащены лицензионным программным комплексами.

Расчеты Р-Т параметров и флюидного режима метаморфизма проведены с использованием хорошо зарекомендовавших себя программных комплексов GEOPATH, TWQ, PERPLEX, основанных на взаимосогласованных базах термодинамических данных $[10,11]$.

\section{Результаты и обсуждение}

Моделирование минеральных ассоџиаџий ксенолитов методом псевдосечений и термобарометрия

Петролого-минералогическое изучение основных ксенолитов в трондьемитах ЛГК было проведено нами ранее [7] в образцах ЛН-101 и ЛН-102 (рис. 1). Взаимоотношения минеральных фаз в ксенолитах демонстрируют, что образование амфибола в них является более поздним процессом по отношению к первичной ассоциации $\mathrm{Opx} \pm \mathrm{Cpx}+\mathrm{Pl}+\mathrm{Qtz}+\mathrm{Ilm}+\mathrm{Mt}$ и было связано, повидимому, с притоком флюидов, связанных с трондьемитами. Поэтому на первом этапе было проведено моделирование первичной ассоциации в системе, не содержащей $\mathrm{H}_{2} \mathrm{O}$ и амфибол. Расчеты проводились посредством минимизации энергии Гиббса для системы $\mathrm{Na}_{2} \mathrm{O}-\mathrm{CaO}-\mathrm{K}_{2} \mathrm{O}-\mathrm{FeO}-\mathrm{MgO}-\mathrm{Al}_{2} \mathrm{O}_{3}-\mathrm{SiO}_{2}-\mathrm{H}_{2} \mathrm{O}-\mathrm{TiO}_{2}-\mathrm{O}_{2}$
(NCKFMASHTO) с заданным валовым составом с использованием программного комплекса PERPLE_X [12], версия 6.7.7 для Windows, с использованием стандартных термодинамических свойств конечных членов твердых растворов из базы данных Т. Холланда и Р. Пауэлла ([11], файл hp11ver.dat).

Ассоциации без амфибола. Для моделирования ассоциации Opx $\pm \mathrm{Cpx}+\mathrm{Pl}+\mathrm{Qtz}+\mathrm{Il} m$ были приняты следующие модели смешения твердых растворов, рекомендованные в PERPLE_X: Opx(W) для ортопироксена, содержащего $\mathrm{Fe}^{3+}$ [13]; $\mathrm{Cpx}(\mathrm{HP})$ для клинопироксена (модифицированная модель [10]); модель «feldspar» для тройного раствора полевого шпата [14]; модель $\operatorname{Ilm}(\mathrm{WPH})$ для твердого раствора ильменит-гейкилитгематит $[13,15,16]$. MnO был исключен из расчетов, поскольку использованные модели твердых растворов клинопироксена и моноклинного амфибола (см. ниже) не включают этот компонент. Его участие может вызвать неадекватное распределение Мn между расчетными составами минералов и появление новых «избыточных» фаз (например, Мn-граната), тем самым повлиять на другие параметры составов, например, магнезиальность.

Составы для моделирования рассчитывались посредством графического анализа изображений в отраженных электронах и подсчета объемных соотношений фаз для конкретных участков шлифов, представительных для выбранной минеральной ассоциации. Для ассоциации $\mathrm{Cpx}+\mathrm{Opx}+\mathrm{Pl}+\mathrm{Qtz}+\mathrm{Ilm}$ в образце ЛН-101 были выбраны два участка (рис. 2 а, б, в, г) со следующими
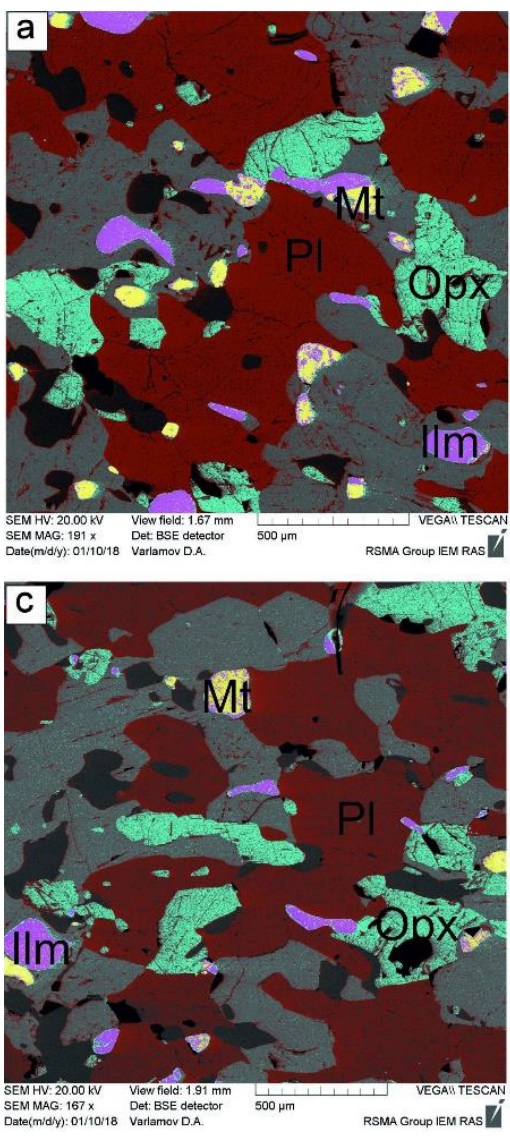
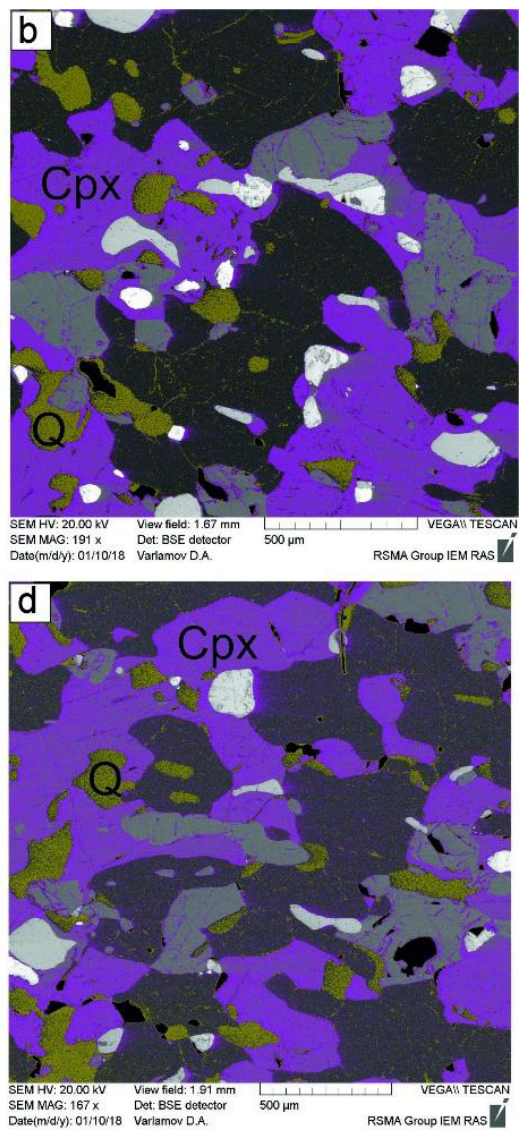

Рис. 2. Изображения минеральных парагенезисов гранулита ЛГК $(a, b-$ обр. ЛН-101_1; $c, d$ - обр. ЛН-101_2). [Fig. 2. Images of mineral paragenesis of granulite from the Lapland Granulite Belt $((a, b)$ sample LN-101_1; $(c, d)$ sample LN-101_2)).] 
составами (мас. \%): (1) $\mathrm{SiO}_{2}$ 52.32, $\mathrm{TiO}_{2}$ 3.93, $\mathrm{Al}_{2} \mathrm{O}_{3}$ 13.85, $\mathrm{FeO} 12.04, \mathrm{MgO} 4.87, \mathrm{CaO} 9.82, \mathrm{Na}_{2} \mathrm{O} 2.66, \mathrm{~K}_{2} \mathrm{O}$ 0.19 и (2) $\mathrm{SiO}_{2}$ 53.24, $\mathrm{TiO}_{2} 2.60, \mathrm{Al}_{2} \mathrm{O}_{3}$ 12.45, $\mathrm{FeO} 12.43$, $\mathrm{MgO}$ 5.71, $\mathrm{CaO} 10.71, \mathrm{Na}_{2} \mathrm{O}$ 2.36, $\mathrm{K}_{2} \mathrm{O}$ 0.23. Из-за неопределенностей графического разграничения фаз среди магнетита, ильменита и пирротина оцененное содержание $\mathrm{Fe}_{2} \mathrm{O}_{3} 2.60$ мас. \% в этой ассоциации принималось как максимальное, а оптимальное содержание этого компонента, определяющее минеральную ассоциацию и составы минералов, рассчитывалось на основе диаграмм Т-М ного» кислорода $\mathrm{O}_{2}$ в системе. Так, для указанных выше составов оптимальным содержанием $\mathrm{O}_{2}$ оказалось заметно ниже, 0.025 мас. \%, что соответствует 0.25 мас. $\% \mathrm{Fe}_{2} \mathrm{O}_{3}$. Значение 0.025 мас. \% $\mathrm{O}_{2}$ было выбрано для дальнейших расчетов. Предварительные расчеты показали, что при определенном давлении в системе с указанным составом появляется гранат. Рассчитанные Р-Т псевдосечения в интервале 5-9 кбар и $600-800^{\circ} \mathrm{C}$

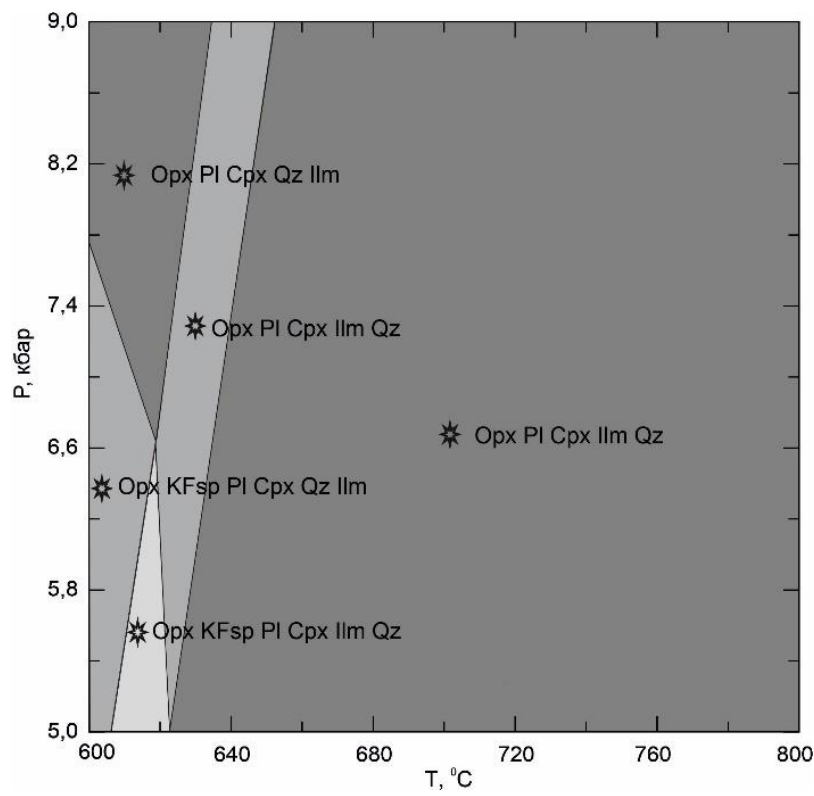

Рис. 3. РТ-псевдосечения для валового анализа образца ЛН-101_1.

[Fig. 3. PT pseudo-sections for elementary analysis of LN101_1 sample.]

Для подтверждения результатов, полученных при моделировании минеральной ассоциации Орх $+\mathrm{Cpx}+$ $+\mathrm{P} 1+\mathrm{Qz}+\mathrm{Ilm}$ в образце ЛН-101, были рассчитаны температуры по равновесию Срх+Орх для 59 пар минералов из этого образца. Для этого применялся программный комплекс winTWQ_2.32 [17] (табл. 4). На рис. 7 результаты расчетов представлены в виде гистограммы. На ней выделяется широкий пик (39 измерений) в интервале $700-760{ }^{\circ} \mathrm{C}$, с максимумом в интервале температур $710-730^{\circ} \mathrm{C}$, оцененных из псевдосечений.

В отличие от ЛН-101, в образце ЛН-102 наряду с пирротином присутствует заметное количество пирита, указывая на смещение равновесия

$$
4 \mathrm{FeS}+1.5 \mathrm{O}_{2}=2 \mathrm{FeS}_{2}+\mathrm{Fe}_{2} \mathrm{O}_{3} \text { (в силикатах) }
$$

(рис. 3, 4) представляют очень простые диаграммы, в которых резко доминирующим является поле ассоциации $\mathrm{Opx}+\mathrm{Cpx}+\mathrm{Pl}+\mathrm{Qz}+\mathrm{Ilm}$. Изоплеты $\mathrm{X}_{\mathrm{mgOpx}}=0.43$ $0.44, \mathrm{Al}_{2} \mathrm{O}_{3}$ в $\mathrm{Opx} 1.2-1.3$ мас. \%, $\mathrm{CaO}$ в Орх 0.6-0.7 мас. $\%, \mathrm{X}_{\mathrm{MgCpx}}=0.56-0.58, \mathrm{Na}_{\mathrm{Cpx}}($ ф.e. $)=0.03-0.05, \mathrm{X}_{\mathrm{anPl}}=$ 0.47-0.48, отражающие составы центральных зон сосуществующих минералов в образце ЛН-101 (рис. 5, 6, табл.1-3), перекрываются и пересекаются в интервале давлений 7.5-7.7 кбар и температур $700-720^{\circ} \mathrm{C}$ для составов первого участка (рис. 2а,б) и 7.2-7.6 кбар и температур 700-730 ${ }^{\circ} \mathrm{C}$ - для второго (рис.2 в, г). При этом относительные содержания Орх (16-18 об. \%), Срх (21-27 об. \%), Pl (43-50 об. \%), Ilm (5 об. \%) и Qz (810 об. \%) близки к подсчитанным соотношениям этих минералов в выбранных участках шлифа ЛН-101: Орх 12 и 13 об. \%, Срх 20 и 29 об. \%, P1 50 и 42 об. \%, Ilm 8 и 5 об. \% и Qz 9 и 10 об. \%, соответственно для участков 1 и 2 (рис. 2 а, б, в, г).

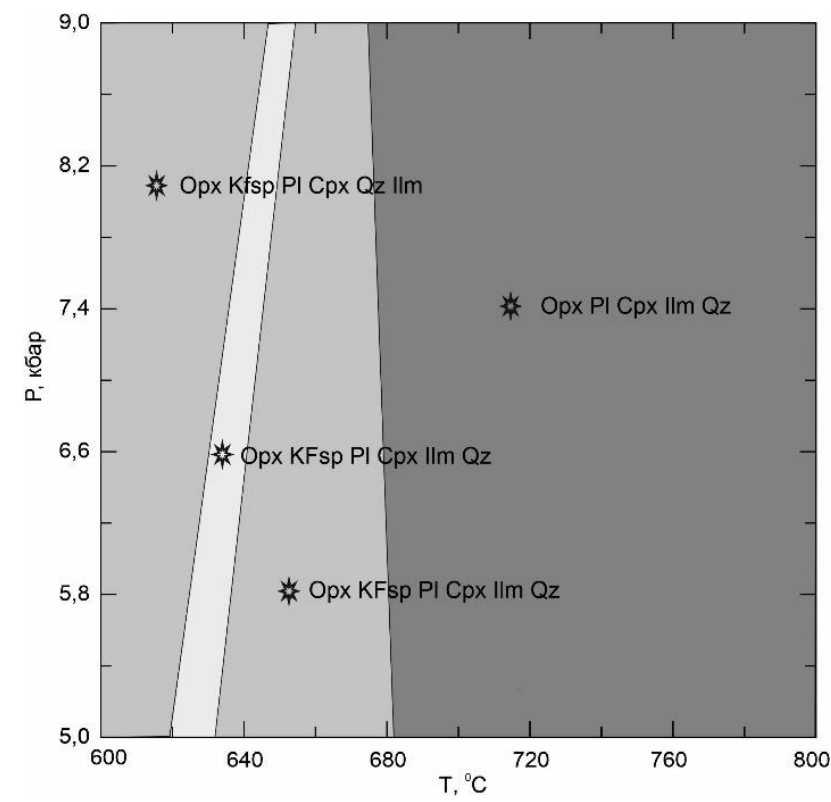

Рис. 4. РТ-псевдосечения для валового анализа образца ЛН-101 2.

[Fig. 4. PT pseudo-sections for elementary analysis of LN101_2 sample.]

вправо. Магнетит же в образце ЛН-102 содержит меньшие концентрации Ti и Al, указывающие также на смещение равновесий

$$
\begin{gathered}
3 \mathrm{FeAl}_{2} \mathrm{O}_{4}+0.5 \mathrm{O}_{2}=\mathrm{Fe}_{3} \mathrm{O}_{4}+3 \mathrm{Al}_{2} \mathrm{O}_{3} \text { (в силикатах) } \\
3 \mathrm{TiFe}_{2} \mathrm{O}_{4}+0.5 \mathrm{O}_{2}=\mathrm{Fe}_{3} \mathrm{O}_{4}+3 \mathrm{FeTiO}_{3}
\end{gathered}
$$

вправо с ростом концентрации «свободного» $\mathrm{O}_{2}$.

Амфиболизация. Появление воды в системе приводит к образованию в ксенолитах паргасит-эденитового амфибола (рис. 8). Для моделирования процесса амфиболизации использовалось амфибол-плагиоклазовое равновесие [18], которое зафиксировало температуры амфиболизации ксенолитов $740-780^{\circ} \mathrm{C}$ при давлении 5.0-5.5 кбар (табл. 5). 


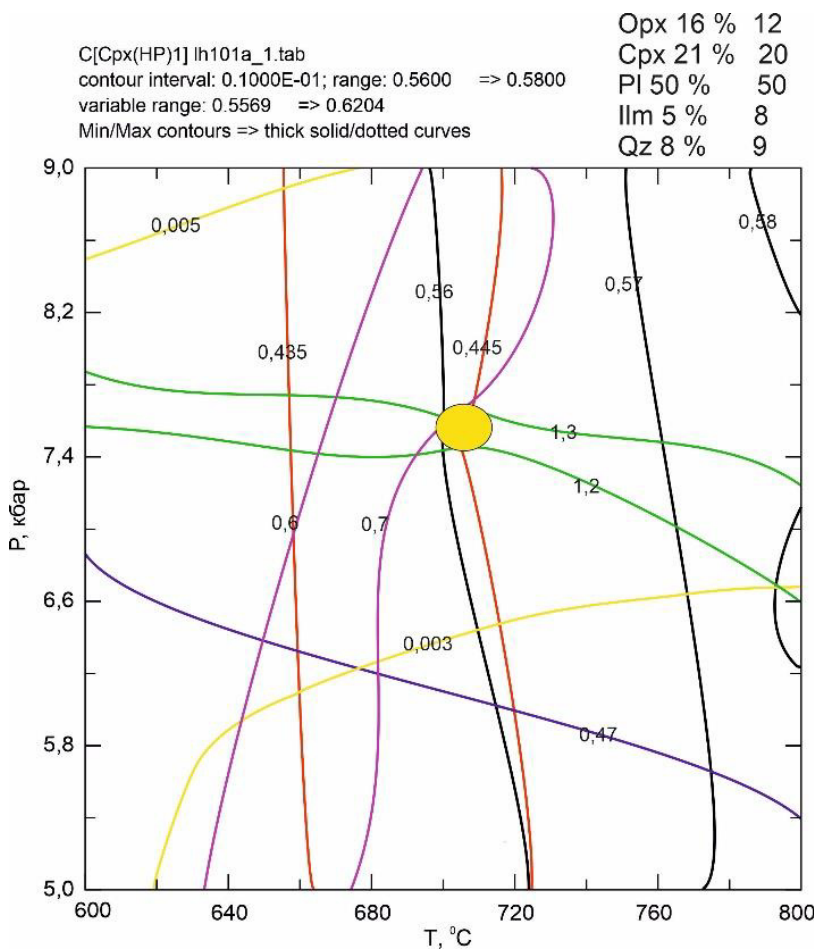

Рис. 5. Изоплеты составов сосуществующих минералов в образце ЛН-101_1.

[Fig. 5. Isopleths of the compositions of coexisting minerals in LN-101_1 sample.]

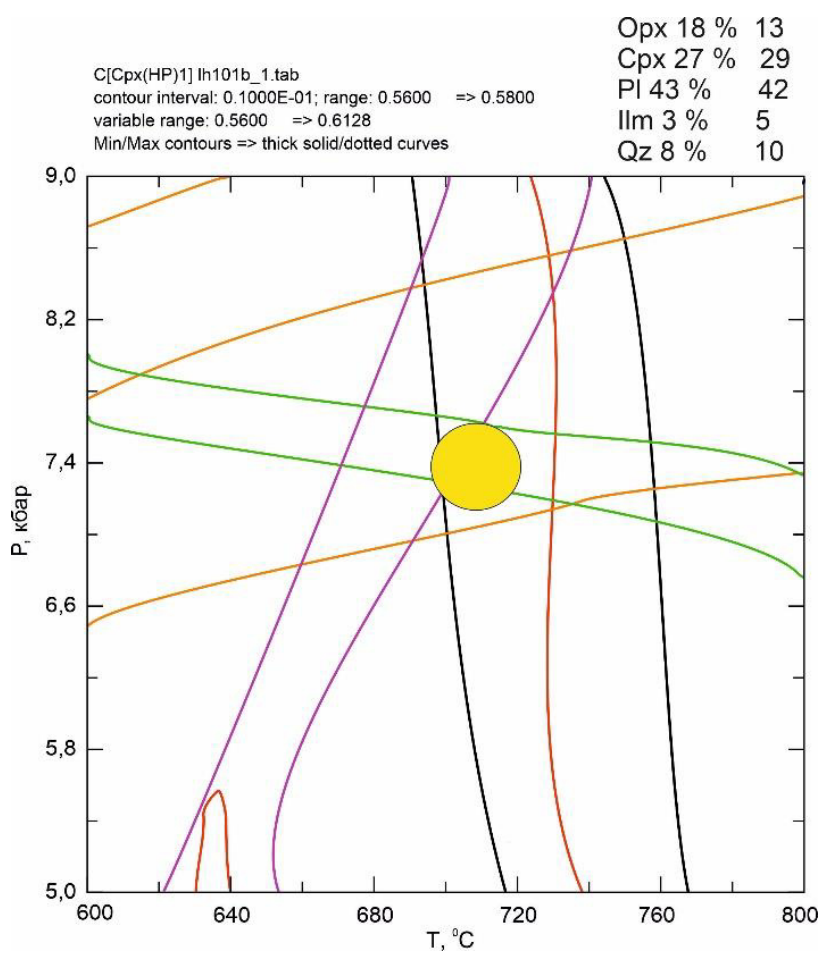

Рис. 6. Изоплеты составов сосуществующих минералов в образце ЛН-101_2.

[Fig. 6. Isopleths of the compositions of coexisting minerals in $\mathrm{LN}-101$ 2 sample.]

Табл. 1. Избранные электронно-зондовые анализы плагиоклазов гранулитов р-на р. Лотта ЛГК [Table 1. Selected electron microprobe analyses of granulite plagioclases from the area of the Lotta river in the Lapland Granulite Belt]

\begin{tabular}{|c|c|c|c|c|c|c|c|c|c|}
\hline № & 35 & 36 & 37 & 38 & 39 & 40 & 41 & 42 & 43 \\
\hline $\begin{array}{l}\text { Компоненты } \\
\text { [Components] }\end{array}$ & Ц & K & K & Ц & Ц & Ц & Ц & Ц & Ц \\
\hline $\mathrm{SiO}_{2}$ & 55.82 & 55.67 & 55.57 & 56.58 & 56.06 & 55.71 & 57.41 & 56.50 & 56.26 \\
\hline $\mathrm{TiO}_{2}$ & 0.00 & 0.04 & 0.14 & 0.08 & 0.09 & 0.00 & 0.21 & 0.06 & 0.00 \\
\hline $\mathrm{Al}_{2} \mathrm{O}_{3}$ & 27.54 & 27.52 & 27.75 & 27.62 & 27.56 & 27.95 & 26.34 & 27.64 & 26.76 \\
\hline $\mathrm{FeO}$ & 0.24 & 0.17 & 0.20 & 0.00 & 0.04 & 0.06 & 0.26 & 0.32 & 0.46 \\
\hline $\mathrm{MnO}$ & 0.20 & 0.00 & 0.07 & 0.09 & 0.00 & 0.00 & 0.00 & 0.00 & 0.00 \\
\hline $\mathrm{MgO}$ & 0.14 & 0.05 & 0.20 & 0.01 & 0.14 & 0.20 & 0.11 & 0.09 & 0.29 \\
\hline $\mathrm{CaO}$ & 10.77 & 10.09 & 10.65 & 10.31 & 10.59 & 10.04 & 9.47 & 9.46 & 9.93 \\
\hline $\mathrm{Na}_{2} \mathrm{O}$ & 5.10 & 6.12 & 5.25 & 5.12 & 5.29 & 5.83 & 5.84 & 5.66 & 6.15 \\
\hline $\begin{array}{l}\text { Cумма } \\
{[\text { Total] }}\end{array}$ & 100.00 & 100.00 & 100.00 & 100.00 & 100.00 & 100.00 & 100.00 & 100.00 & 100.00 \\
\hline \multicolumn{10}{|c|}{$\begin{array}{l}\text { Количество ионов в пересчете на } 8(\mathrm{O}) \\
{[\text { The number of ions in terms of } 8(\mathrm{O})]}\end{array}$} \\
\hline $\mathrm{Si}$ & 2.51 & 2.50 & 2.50 & 2.54 & 2.52 & 2.50 & 2.51 & 2.53 & 2.53 \\
\hline $\mathrm{Ti}$ & 0.00 & 0.00 & 0.00 & 0.00 & 0.00 & 0.00 & 0.01 & 0.00 & 0.00 \\
\hline $\mathrm{Al}$ & 1.46 & 1.46 & 1.47 & 1.46 & 1.46 & 1.48 & 1.39 & 1.46 & 1.42 \\
\hline $\mathrm{Fe}$ & 0.01 & 0.01 & 0.01 & 0.00 & 0.00 & 0.00 & 0.01 & 0.01 & 0.02 \\
\hline $\mathrm{Mn}$ & 0.01 & 0.00 & 0.00 & 0.00 & 0.00 & 0.00 & 0.00 & 0.00 & 0.00 \\
\hline $\mathrm{Mg}$ & 0.01 & 0.00 & 0.01 & 0.00 & 0.01 & 0.01 & 0.01 & 0.01 & 0.02 \\
\hline $\mathrm{Ca}$ & 0.52 & 0.49 & 0.51 & 0.49 & 0.51 & 0.48 & 0.45 & 0.45 & 0.48 \\
\hline $\mathrm{Na}$ & 0.44 & 0.53 & 0.46 & 0.44 & 0.46 & 0.51 & 0.51 & 0.49 & 0.54 \\
\hline
\end{tabular}


Табл. 2. Избранные электронно-зондовые анализы клинопироксенов гранулитов р-на р. Лотта ЛГК

[Table 2. Selected electron microprobe analyses of granulite clinopyroxenes from the area of the Lotta river in the Lapland Granulite Belt]

\begin{tabular}{|c|c|c|c|c|c|c|c|c|c|}
\hline $\begin{array}{c}\text { №/Компоненты } \\
\text { [No. Components] }\end{array}$ & 17 & 2 & 3 & 4 & 5 & 6 & 7 & 8 & 9 \\
\hline $\mathrm{SiO}_{2}$ & 49.98 & 50.55 & 49.81 & 50.49 & 49.99 & 50.71 & 50.18 & 50.68 & 50.33 \\
\hline $\mathrm{TiO}_{2}$ & 0.25 & 0.31 & 0.38 & 0.36 & 0.44 & 0.36 & 0.31 & 0.36 & 0.24 \\
\hline $\mathrm{Al}_{2} \mathrm{O}_{3}$ & 2.23 & 2.28 & 2.12 & 2.21 & 2.13 & 2.41 & 2.22 & 2.09 & 2.26 \\
\hline $\mathrm{FeO}$ & 14.69 & 14.03 & 14.23 & 14.08 & 13.84 & 14.52 & 13.27 & 13.65 & 14.05 \\
\hline $\mathrm{MnO}$ & 0.54 & 0.86 & 0.64 & 0.69 & 0.39 & 0.50 & 0.45 & 0.33 & 0.47 \\
\hline $\mathrm{MgO}$ & 10.25 & 10.24 & 10.75 & 10.73 & 10.87 & 10.51 & 10.42 & 11.00 & 10.77 \\
\hline $\mathrm{CaO}$ & 21.20 & 21.43 & 21.50 & 21.04 & 21.58 & 20.64 & 22.24 & 21.40 & 21.11 \\
\hline $\mathrm{Na}_{2} \mathrm{O}$ & 0.81 & 0.26 & 0.57 & 0.33 & 0.58 & 0.27 & 0.70 & 0.48 & 0.53 \\
\hline $\begin{array}{l}\text { Cумма } \\
\text { [Total] }\end{array}$ & 100.00 & 100.00 & 100.00 & 100.00 & 100.00 & 100.00 & 100.00 & 100.00 & 100.00 \\
\hline \multicolumn{10}{|c|}{$\begin{array}{l}\text { Количество ионов в пересчете на } 6(\mathrm{O}) \\
{[\text { The number of ions in terms of } 6(\mathrm{O})]}\end{array}$} \\
\hline $\mathrm{Si}$ & 1.92 & 1.94 & 1.92 & 1.93 & 1.92 & 1.94 & 1.92 & 1.94 & 1.93 \\
\hline $\mathrm{Ti}$ & 0.01 & 0.01 & 0.01 & 0.01 & 0.01 & 0.01 & 0.01 & 0.01 & 0.01 \\
\hline $\mathrm{Al}$ & 0.10 & 0.10 & 0.10 & 0.10 & 0.10 & 0.11 & 0.10 & 0.09 & 0.10 \\
\hline $\mathrm{Fe}$ & 0.47 & 0.45 & 0.46 & 0.45 & 0.44 & 0.46 & 0.43 & 0.44 & 0.45 \\
\hline $\mathrm{Mn}$ & 0.02 & 0.02 & 0.02 & 0.02 & 0.01 & 0.02 & 0.01 & 0.01 & 0.02 \\
\hline $\mathrm{Mg}$ & 0.59 & 0.59 & 0.62 & 0.61 & 0.62 & 0.60 & 0.60 & 0.63 & 0.62 \\
\hline $\mathrm{Ca}$ & 0.87 & 0.88 & 0.89 & 0.86 & 0.89 & 0.84 & 0.91 & 0.88 & 0.87 \\
\hline $\mathrm{Na}$ & 0.06 & 0.02 & 0.04 & 0.02 & 0.04 & 0.02 & 0.05 & 0.04 & 0.04 \\
\hline
\end{tabular}

Табл. 3. Избранные электронно-зондовые анализы ортопироксенов гранулитов р-на р.Лотта ЛГК [Table 3. Selected electron microprobe analyses of granulite orthopyroxenes from the area of the Lotta river in the Lapland Granulite Belt]

\begin{tabular}{|c|c|c|c|c|c|c|c|c|}
\hline № & 16 & 20 & 26 & 29 & 33 & 18 & 21 & 25 \\
\hline $\begin{array}{l}\text { Компоненты } \\
\text { [Components] }\end{array}$ & Ц & Ц & Ц & Ц & Ц & Ц & K & K \\
\hline $\mathrm{SiO}_{2}$ & 49.68 & 50.55 & 49.37 & 49.88 & 49.50 & 49.33 & 50.11 & 49.96 \\
\hline $\mathrm{TiO}_{2}$ & 0.17 & 0.14 & 0.07 & 0.00 & 0.31 & 0.00 & 0.00 & 0.14 \\
\hline $\mathrm{Al}_{2} \mathrm{O}_{3}$ & 1.26 & 1.33 & 1.31 & 1.37 & 0.98 & 1.29 & 1.28 & 1.24 \\
\hline $\mathrm{FeO}$ & 32.93 & 31.77 & 32.66 & 32.29 & 32.18 & 32.50 & 32.26 & 32.26 \\
\hline $\mathrm{MnO}$ & 0.83 & 0.92 & 1.19 & 0.98 & 1.26 & 1.14 & 1.14 & 1.23 \\
\hline $\mathrm{MgO}$ & 14.56 & 14.58 & 14.56 & 14.41 & 14.66 & 14.36 & 14.59 & 14.20 \\
\hline $\mathrm{CaO}$ & 0.57 & 0.70 & 0.76 & 0.69 & 0.91 & 0.60 & 0.53 & 0.88 \\
\hline $\mathrm{Na}_{2} \mathrm{O}$ & 0.00 & 0.00 & 0.00 & 0.22 & 0.15 & 0.49 & 0.00 & 0.08 \\
\hline Сумма & 100.00 & 100.00 & 100.00 & 100.00 & 100.00 & 100.00 & 100.00 & 100.00 \\
\hline \multicolumn{9}{|c|}{$\begin{array}{l}\text { Количество ионов в пересчете на } 6(\mathrm{O}) \\
{[\text { The number of ions in terms of } 6(\mathrm{O})]}\end{array}$} \\
\hline $\mathrm{Si}$ & 1.96 & 1.98 & 1.95 & 1.96 & 1.95 & 1.95 & 1.97 & 1.97 \\
\hline $\mathrm{Ti}$ & 0.01 & 0.00 & 0.02 & 0.00 & 0.01 & 0.00 & 0.00 & 0.00 \\
\hline $\mathrm{Al}$ & 0.06 & 0.06 & 0.06 & 0.05 & 0.06 & 0.06 & 0.06 & 0.06 \\
\hline $\mathrm{Fe}$ & 1.08 & 1.04 & 1.08 & 1.06 & 1.08 & 1.07 & 1.06 & 1.06 \\
\hline $\mathrm{Mn}$ & 0.03 & 0.03 & 0.04 & 0.03 & 0.04 & 0.04 & 0.04 & 0.04 \\
\hline $\mathrm{Mg}$ & 0.85 & 0.85 & 0.86 & 0.84 & 0.86 & 0.84 & 0.85 & 0.83 \\
\hline $\mathrm{Ca}$ & 0.02 & 0.03 & 0.03 & 0.03 & 0.04 & 0.03 & 0.02 & 0.04 \\
\hline $\mathrm{Na}$ & 0.00 & 0.00 & 0.00 & 0.02 & 0.01 & 0.04 & 0.00 & 0.01 \\
\hline
\end{tabular}


Табл. 4. Т-Р условия равновесия клинопироксен + ортопироксен + плагиоклаз + кварц в неамфиболизированной части ксенолитов, оцененные с помощью программы TWQ 2.32 [10]

[Table 4. T-P conditions of the clinopyroxene + orthopyroxene + plagioclase + quartz equilibrium in non-amphibolised sections of xenoliths estimated using the TWQ 2.32 software package [10]]

\begin{tabular}{|c|c|c|c|c|}
\hline P1, № & Орх, № & Срх, № & $\mathrm{T},{ }^{0} \mathrm{C}$ & Р, кбар \\
\hline $40^{*}$ & 16 & 9 & 804 & 6.2 \\
\hline 41 & 18 & 9 & 804 & 6.4 \\
\hline 43 & 20 & 17 & 862 & 6.0 \\
\hline 43 & 21 & 17 & 839 & 6.0 \\
\hline 38 & 29 & 6 & 802 & 6.2 \\
\hline 39 & 29 & 6 & 800 & 6.2 \\
\hline
\end{tabular}

*№ анализов, см. таблицы $1,2,3$.

*See No. of analyses in Tables 1, 2, 3 .

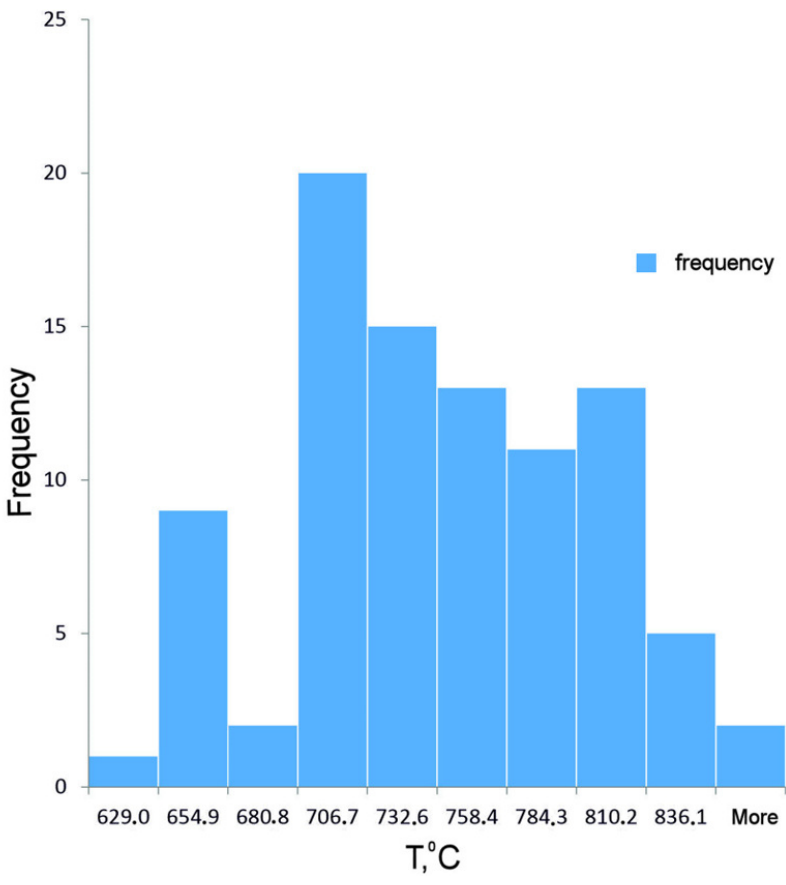

Рис. 7. Гистограмма рассчитанных температур по равновесию Сpx+Opx [15].

[Fig. 7. The histogram of the calculated temperatures based on the $\mathrm{Cpx}+\mathrm{Opx}$ equilibrium [15].]

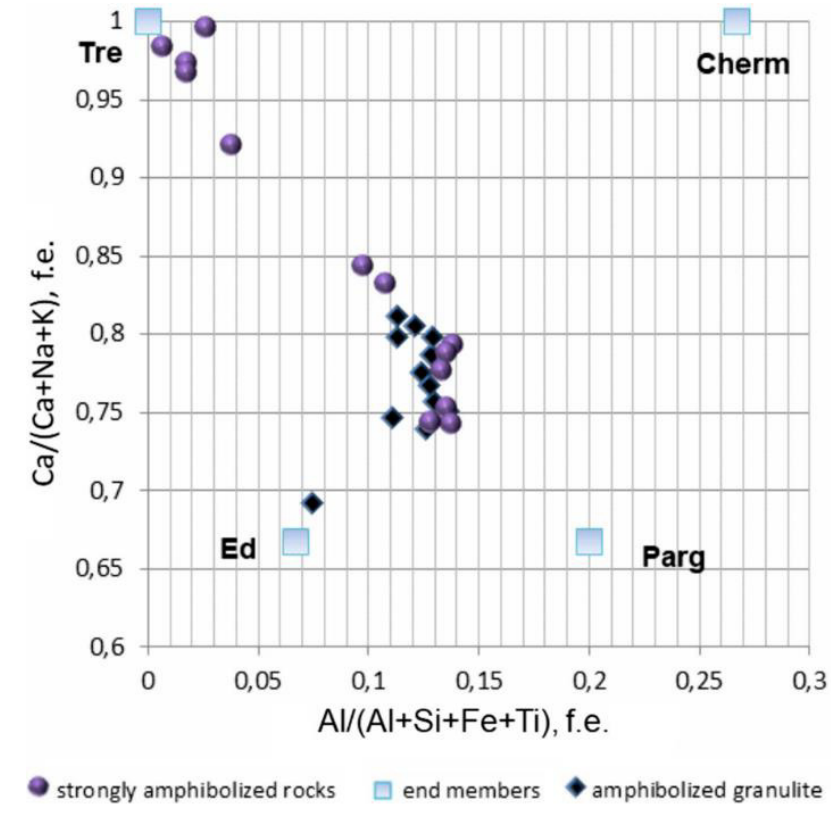

Рис. 8. Составы амфиболов основных ксенолитов в трондьемитах р-на р. Лотта Центральной зоны Лапландского гранулитового комплекса.

[Fig. 8. Compositions of amphiboles of mafic xenoliths in trondhjemites in the area of the Lotta river in the Central Zone of the Lapland Granulite Belt.]

Табл. 5. Т-Р условия амфиболизации гранулита,

определённые с помощью значений амфибол-плагиоклазового равновесия [11]

[Table 5. T-P conditions of granulite amphibolisation determined by means of amphibole-plagioclase equilibrium [11]]

\begin{tabular}{|c|c|c|c|c|c|c|c|}
\hline $\begin{array}{c}\text { Amp, №/Компоненты } \\
\text { [Amp, No. /Components] }\end{array}$ & $24 Ц$ & $25 \mathrm{~K}$ & $27 Ц$ & $28 \mathrm{~K}$ & $35 \mathrm{~K}$ & $42 Ц$ & $43 \mathrm{~K}$ \\
\hline 1 & 2 & 3 & 4 & 5 & 6 & 7 & 8 \\
\hline $\mathrm{SiO}_{2}$ & 42.49 & 42.16 & 42.99 & 42.38 & 43.44 & 43.26 & 42.86 \\
\hline $\mathrm{TiO}_{2}$ & 1.71 & 1.32 & 1.88 & 1.71 & 0.80 & 1.34 & 1.57 \\
\hline $\mathrm{Al}_{2} \mathrm{O}_{3}$ & 11.65 & 11.67 & 11.94 & 11.97 & 11.82 & 11.14 & 11.52 \\
\hline $\mathrm{FeO}$ & 20.59 & 20.34 & 20.37 & 20.98 & 19.67 & 19.90 & 20.81 \\
\hline $\mathrm{MgO}$ & 8.39 & 8.50 & 8.26 & 8.34 & 9.31 & 8.91 & 8.40 \\
\hline $\mathrm{MnO}$ & 0.38 & 0.28 & 0.35 & 0.13 & 0.33 & 0.31 & 0.29 \\
\hline $\mathrm{CaO}$ & 12.24 & 12.19 & 11.09 & 12.23 & 12.14 & 12.46 & 12.11 \\
\hline $\mathrm{Na}_{2} \mathrm{O}$ & 1.47 & 1.35 & 1.44 & 1.14 & 1.16 & 1.56 & 1.21 \\
\hline $\mathrm{K}_{2} \mathrm{O}$ & 1.25 & 1.32 & 1.29 & 0.95 & 0.99 & 1.24 & 1.10 \\
\hline $\mathrm{F}$ & 0.00 & 0.00 & 0.00 & 0.00 & 0.00 & 0.00 & 0.00 \\
\hline
\end{tabular}


Продолжение Табл. 5

[Continued Table 5]

\begin{tabular}{|c|c|c|c|c|c|c|c|}
\hline 1 & 2 & 3 & 4 & 5 & 6 & 7 & 8 \\
\hline$\underline{\mathrm{Cl}}$ & $\underline{0.00}$ & $\underline{0.00}$ & $\underline{0.00}$ & $\underline{0.00}$ & $\underline{0.00}$ & $\underline{0.00}$ & $\underline{\underline{0.00}}$ \\
\hline $\begin{array}{c}\text { Сумма } \\
{[\text { Total] }}\end{array}$ & 100.17 & 99.13 & 99.61 & 99.83 & 99.66 & 100.12 & 99.87 \\
\hline $\mathrm{Pl}$ & & & & & & & \\
\hline $\mathrm{xAb}$ & 0.53 & 0.53 & 0.53 & 0.53 & 0.53 & 0.53 & 0.53 \\
\hline $\mathrm{xAn}$ & 0.47 & 0.47 & 0.47 & 0.47 & 0.47 & 0.47 & 0.47 \\
\hline $\mathrm{T},{ }^{0} \mathrm{C}$ & $\mathbf{7 6 6 . 3}$ & $\mathbf{7 5 6 . 0}$ & $\mathbf{7 7 9 . 9}$ & $\mathbf{7 6 2 . 9}$ & $\mathbf{7 4 5 . 6}$ & $\mathbf{7 3 9 . 9}$ & $\mathbf{7 6 0 . 4}$ \\
\hline Р,кбар & $\mathbf{5 . 0 0}$ & $\mathbf{5 . 3 3}$ & $\mathbf{4 . 8 6}$ & $\mathbf{5 . 2 9}$ & $\mathbf{5 . 5 1}$ & $\mathbf{5 . 1 9}$ & $\mathbf{5 . 0 3}$ \\
\hline
\end{tabular}

\section{Флюидные включения}

Флюидные включения были изучены в кварце и представлены углекислотными и водно-солевыми разностями. Углекислотные включения относительно мелкие размером 5-15 мкм, реже встречаются до 20-25 мкм. По текстурным особенностям они представлены только первично-вторичными разностями (маркируют залеченные трещины в пределах отдельных зерен) (рис. 9). Температуры гомогенизации и соответственно плотности углекислотных включений варьируют от 4.2 до $8.1^{\circ} \mathrm{C}$ и от 0.901 до 0.875 г $/ \mathrm{cm}^{3}$. Температура плавления включений изменяется от $-57.1^{\circ} \mathrm{C}$ до $-59.8^{\circ} \mathrm{C}$.

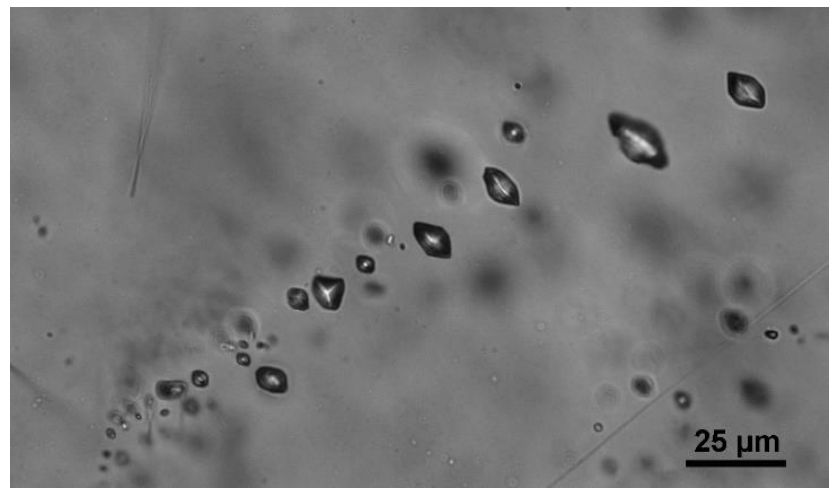

Рис. 9. Микрофотография первично-вторичных углекислотных включений в кварце.

[Fig. 9. A micrograph of primary-secondary carbon dioxide inclusions in quartz.]

\section{Выводы}

Новые уточненные оценки Р-Т параметров пика метаморфизма ЛГК и данные о флюидных включениях подтвердили выводы [7, 19, 20], что образование трондьемитовых магм, вероятно, происходило на глубинах порядка 25-30 км. По мере подъема с 20-25 км магмы захватывали ксенолиты основных пород [2, 4], активно взаимодействуя с ними. Процесс амфиболизации ксенолитов имел место при температурах 740 $780^{\circ} \mathrm{C}$ и давлении 5.0-5.5 кбар, а вариации состава амфибола указывают на то, что этот процесс протекал на фоне общего остывания. Амфиболизация ксенолитов связана с проникновением в них существенно водного флюида из остывающей трондьемитовой магмы, что подтверждается резким преобладанием водно-солевых (1-20 мас. \% $\mathrm{NaCl}$ эквивалента) и подчиненным коли-
Водно-солевые включения обычно плоские, светлые, удлиненно-овальные или неправильной формы, часто с оттянутыми концами размером, не превышающим 25 мкм. Локализуются во всех случаях вдоль залеченных трещин, не пересекающих границы отдельных зерен (первично-вторичные) (рис.10). Начальное плавление льда во включениях происходит в интервале от -58 до $-55^{\circ} \mathrm{C}$, что указывает на присутствие в растворе $\mathrm{CaCl}_{2}$. Конечная температура плавления льда варьирует от $-16.7^{\circ} \mathrm{C}$ до $-13.1^{\circ} \mathrm{C}$, что соответствует содержанию NaCl-эквивалента 17.0920.19 мас. $\%$.

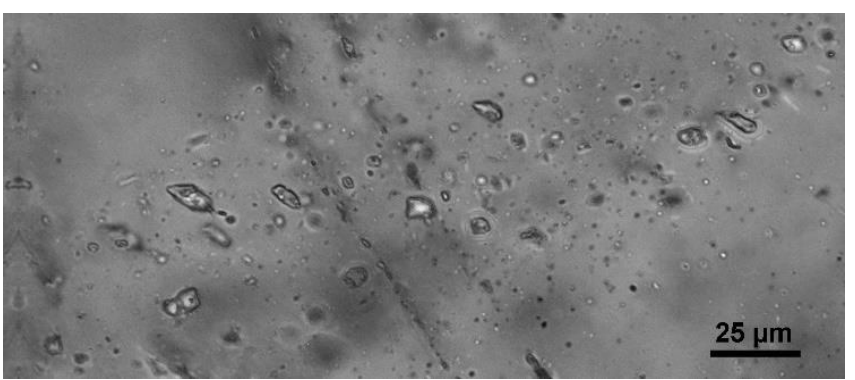

Рис. 10. Микрофотография первично-вторичных водно-солевых включений в кварце.

[Fig. 10. A micrograph of primary-secondary water-salt inclusions in quartz.]

чеством углекислых включений в минералах гранитоидов. Несмотря на активное флюидное взаимодействие расплава и ксенолитов, признаков термального воздействия не установлено.

Конфликт интересов: Авторы декларируют отсутствие явных и потенциальных конфликтов интересов, связанных с публикацией настоящей статьи.

\section{ЛИТЕРАТУРА}

1. Митрофанов Ф. П., Кравцова Е. И., Мануилова М. М. Раннедокембрийские гранитоидные формации. Москва, Наука, 1974. 292 с.

2. Козлов Н. Е., Козлова Н. Е. О генезисе гранатовых плагиогранитоидов Лапландского гранулитового пояса // Becmник МГТУ. 1998. № 1. С. 43-52. 
3. Mints M. V., Kaulina T. V., Konilov A. N., Krotov A. V., Stupak V. M. The thermal and geodynamic evolution of the Lapland granulite belt: Implications for thermal structure of the lower crust during granulite-facies metamorphism // Gondwana Re$\begin{array}{lllll}\text { search. } & 2007 . & \text { Vol. } & 12 . & \text { P. }\end{array}$ DOI: 10.1016/j.gr.2006.10.007

4. Каулина Т. В., Нерович Л. И., Баянова Т. Б., Япаскурт В. О. Последовательность геологических процессов в Центральной и Северо-Восточной части Лапландского гранулитового пояса: изотопно-геохимические данные по циркону и результаты геолого-петрологических исследований // Геохимия. 2014. № $7 . \quad$ C. $625-645$. DOI: $10.7868 / \mathrm{S} 0016752514050069$

5. Glebovitsky V., Marker M., Alexejev N., Bridgwater D., Sedova I., Salnikova E., Berezhnaya N., Age, evolution and regional setting of the Palaeoproterozoic Umba igneous suite in the Kolvitsa-Umba zone, Kola Peninsula: Constrains from new geological, geochemical and U-Pb zircon data // Precambrian Research. 2001. Vol. 105. P. 247-267. DOI: 10.1016/S03019268(00)00114-5

6. Marker M., Henkel H., Lee M.K. Combined gravity and magnetic modelling of the Tanaelv and Lapland Granulite Belts, Polar Profile, Northern Baltic Shield // The European Geotraverse: Integrative Studies. Strasbourg. European Science Foundation. 1990. P. 67-76.

7. Бутвина В. Г., Голунова М. А., Вирюс А. А. Р-Т и флюидные условия взаимодействия основных ксенолитов и плагиогранитов р-на р. Лотта Центральной зоны Лапландского гранулитового комплекса // Труды Ферсмановской научной сессии ГИ КНЦ РАН. 2019. 16. С. 33-38 DOI: $10.31241 /$ FNS.2019.16.007

8. Bakker R. J. Package FLUIDS 1. Computer programs for analysis of fluid inclusion data and for modelling bulk fluid properties // Chem. Geol. 2003. Vol. 194. P. 3-23. DOI: $10.1016 / \mathrm{S} 0009-2541(02) 00268-1$

9. Duan Z., Møller N., Weare J. H. A general equation of state for supercritical fluid mixtures and molecular dynamics simulation of mixture PVTX properties // Geochim. Cosmochim. Acta. 1996. Vol. 60. P. 1209-1216. DOI: 10.1016/00167037(96)00004-X

10. Holland T., Powell R. Thermodynamics of order-disorder in minerals: II. Symmetric formalism applied to solid solutions // American Mineralogist. 1996. Vol. 81(11-12). P. 1425-1437. DOI: 10.2138/am-1996-11-1215

11. Holland T. J. B., Powell R. An improved and extended inter- nally consistent thermodynamic dataset for phases of petrological interest, involving a new equation of state for solids // Journal of Metamorphic Geology. 2011. Vol. 29(3). P. 333-383. DOI: $10.1111 / j .1525-1314.2010 .00923 . x$

12. Connolly J. A. Computation of phase equilibria by linear programming: a tool for geodynamic modeling and its application to subduction zone decarbonation // Earth and Planetary Science Letters. 2005. Vol. 236(1-2). P. 524-541. DOI: $10.1016 /$ j.epsl.2005.04.033

13. White R. W., Powell R., Holland T. J. B., Johnson T. E., Green E. C. R. New mineral activity-composition relations for thermodynamic calculations in metapelitic systems // Journal of Metamorphic Geology. 2014a. Vol. 32(3). P. 261-286. DOI: $10.1111 / \mathrm{jmg} .12071$

14. Fuhrman, M. L., Lindsley, D. H. Feldspar minerals // Amer Miner. 1988. Vol. 73. P. 201-215. DOI: 10.1007/978-3-64272594-4_9

15. White R. W., Powell R., Holland T. J. B., Worley B. A. The effect of $\mathrm{TiO}_{2}$ and $\mathrm{Fe}_{2} \mathrm{O}_{3}$ on metapelitic assemblages at greenschist and amphibolite facies conditions: mineral equilibria calculations in the system $\mathrm{K}_{2} \mathrm{O}-\mathrm{FeO}-\mathrm{MgO}-\mathrm{Al}_{2} \mathrm{O}_{3}-\mathrm{SiO}_{2}-\mathrm{H}_{2} \mathrm{O}-$ $\mathrm{TiO}_{2}-\mathrm{Fe}_{2} \mathrm{O}_{3}$ // Journal of Metamorphic Geology. 2000. Vol. 18(5). P. 497-512. DOI: 10.1046/j.1525-1314.2000.00269.x

16. White R. W., Powell R., Johnson T. E. The effect of Mn on mineral stability in metapelites revisited: new $\mathrm{a}-\mathrm{x}$ relations for manganese-bearing minerals // Journal of Metamorphic Geology. 20146. Vol. 32(8). P. 809-828. DOI: 10.1111/jmg.12095

17. Berman R. G. WinTWQ (version 2.3): A software package for performing internally-consistent thermobarometric calculations // Geological Survey of Canada Open File 5462. 2007.

18. Blundy J. D., Holland T. J. B. Calcic amphibole equilibria and a new amphibole-plagioclase geothermometer // Contribution to Mineralogy and Petrology. 1990. Vol. 104. P. 208-224.

19. Сафонов О. Г., Реутский В. Н., Голунова М. А., Бутвина В. Г., Япаскурт В. О., Варламов Д. А. Различные источники углерода во флюидах гранитоидов в гранулитовых комплексах. XXI симпозиум по геохимии изотопов имени академика А.П. Виноградова. Москва, Россия, 15-17 ноября 2016.

20. Сафонов О. Г., Реутский В. Н., Голунова М. А., Бутвина В. Г., Япаскурт В. О., Варламов Д. А., Щербаков В. Д., ван Риннен Д. Д. Изотопные характеристики углерода как индикатор источника высокотемпературных гранитоидов в гранулитовых комплексах. Геодинамика раннего Докембрия: сходство и различия с Фанерозоем. Материалы конференции. Петрозаводск, 29-31 мая 2017. С. 216-218. 
UDC 552.13

ISSN 1609-0691

DOI: https://doi.org/10.17308/geology.2021.2/3487

Received: 30.03 .2021

Accepted: 20.05.2021

Published online: 30.06 .2021

\title{
Thermobarometry of mafic xenoliths in the trondhjemites from the area of the Lotta river in the Central Zone of the Lapland Granulite Belt
}

\author{
(C2021 V. G. Butvina ${ }^{\circledR}$, M. A. Golunova, O. G. Safonov \\ Korzhinsky's Institute of Experimental Mineralogy of the Russian Academy of Science, \\ 4 Akademika Osipyana ul., Chernogolovka 142432, Moscow region, Russian Federation
}

\begin{abstract}
Introduction: Earlier results of petrological and mineralogical studies of xenoliths in garnetiferous trondhjemites from the Central Zone of the Lapland Granulite Belt in the area of the Lotta river were used to model their mineral associations by means of the pseudo-cut method.

Methodology: The calculations of P-T parameters and fluid evolution during metamorphism were conducted by using the well-proven GEOPATH, TWQ, PERPLEX software systems based on mutually agreed thermodynamic data bases. The compositions of the minerals were determined by a CamScan MV2300 (VEGA TS 5130MM) electron microscope with a Link INCA Energy energy dispersive analysis system. Fluid inclusions in metamorphic rocks were studied in plates 200-300 $\mu \mathrm{m}$ thick, polished on both sides, using a Linkam system with an operational temperature range from $-196^{\circ} \mathrm{C}$ to $600^{\circ} \mathrm{C}$ (THMSG 600) and automatic modes of sample heating and cooling at a rate of 0.1 to $90 \% \mathrm{~min}$.

Results and discussion: 1. Modelling of mineral associations of xenoliths by the pseudo-cut method and thermobarometry: the calculated P-T pseudo-cuts in the range of $5-9 \mathrm{kbar}$ and $600-800^{\circ} \mathrm{C}$ are represented by simple diagrams dominated by the field of $\mathrm{Opx}+\mathrm{Cpx}+\mathrm{Pl}+\mathrm{Qz}+\mathrm{Ilm}$ association. Using the winTWQ_2.32 software package $\mathrm{Cpx}+\mathrm{Opx}$, equilibrium temperatures were calculated for 59 pairs of minerals. The amphibole-plagioclase equilibrium was used to simulate the amphibolisation process which recorded the temperatures of xenolith amphibolisation of $740-780^{\circ} \mathrm{C}$ at a pressure of $5.0-5.5 \mathrm{kbar}$. 2. Fluid inclusions: fluid inclusions were studied in quartz and presented by carbon-dioxide and water-salt varieties.

Conclusions: Xenolith amphibolisation is associated with the penetration of substantially aqueous fluid from the cooling trondhjemite magma. This is proved by an evident predominance of water-salt (17-20 wt. $\%$ of $\mathrm{NaCl}$ equivalent) and subordinate quantity of carbon dioxide inclusions in granitoid minerals. Despite active fluidic interaction between the melt and xenoliths, no signs of thermal effect were established.

Keywords: Lapland granulite complex, trondhjemite, granulite, basic xenoliths, P-T parameters, fluid in-
\end{abstract} clusions, amphibolisation.

Funding: The work was carried out within the framework of the AAAA-A18-118020590148-3 state assignment of the Institute of Experimental Mineralogy of the Russian Academy of Science for 2021.

For citation: Butvina V. G., Golunova M. A., Safonov O. G.Thermobarometry of mafic xenoliths in the trondhjemites from the area of the Lotta river in the Central Zone of the Lapland Granulite Belt. Vestnik Voronezhskogo gosudarstvennogo universiteta. Seriya: Geologiya-Proceedings of Voronezh State University. Series: Geology, 2021, no. 2, pp. 41-51. DOI: https://doi.org/10.17308/geology.2021.2/3487

Conflict of interests: The authors declare the absence of obvious and potential conflicts of interest related to the publication of this article.

The content is available under Creative Commons Attribution 4.0 License.

Valentina G. Butvina, e-mail: butvina@iem.ac.ru 


\section{REFERENCE}

1. Mitrofanov F. P., Kravtsova E. I., Manuilova M. M. Rannedokembriiskie granitoidnye formatsii [Early Precambrian granitoid formations]. Moscow, Nauka publ., 1974, 292 p. (In Russ.)

2. Kozlov N. E., Kozlova N. E. O genezise granatovykh plagiogranitoidov Laplandskogo granulitovogo poyasa [On the genesis of garnet plagiogranitoids of the Lapland granulite belt]. Vestnik of MSTU Bulletin of MSTU, 1998, vol. 1, pp. 43-52. (In Russ.)

3. Mints M. V., Kaulina T. V., Konilov A. N., Krotov A. V., Stupak V. M. The thermal and geodynamic evolution of the Lapland granulite belt: Implications for thermal structure of the lower crust during granulite-facies metamorphism. Gondwana Research, 2007, vol.12, pp. 252-267. DOI: 10.1016/j.gr.2006.10.007

4. Kaulina T. V., Nerovich L. I., Bayanova T. B., Yapaskurt V. O. Sequence of geological processes in the Central and North-Eastern part of the Lapland granulite belt: isotope-geochemical data on zircon and results of geological and petrological studies. Geohimia - Geochemistry, 2014, no. 7, pp. 625-645. (In Russ.) DOI: $10.7868 / \mathrm{S} 0016752514050069$

5. Glebovitsky V., Marker M., Alexejev N., Bridgwater D., Sedova I., Salnikova E., Berezhnaya N. Age, evolution and regional setting of the Palaeoproterozoic Umba igneous suite in the Kolvitsa-Umba zone, Kola Peninsula: Constrains from new geological, geochemical and U-Pb zircon data. Precambrian Research, 2001, vol.105, pp. 247-267. DOI: 10.1016/S0301-9268(00)00114-5

6. Marker M., Henkel H., Lee M.K. Combined gravity and magnetic modelling of the Tanaelv and Lapland Granulite Belts, Polar Profile, Northern Baltic Shield. The European Geotraverse: Integrative Studies. Strasbourg. European Science Foundation, 1990, pp. 67-76

7. Butvina V. G., Golunova M. A., Viryus A. A. P-T and fluid conditions of interaction between mafic xenolithes and plagiogranites in the Lotta River Area, Lapland Granulite Belt. Trudy Fersmanovskaya nauchnoi sessii GI KSC RAS - Proceedings of the Fersman Scientific Session of the State Institute of the CSC RAS, 2019, 16, pp. 33-38. https://doi.org/10.31241/FNS.2019.16.007. (In Russ.)

8. Bakker R. J. Package FLUIDS 1. Computer programs for analysis of fluid inclusion data and for modelling bulk fluid properties. Chem. Geol., 2003, vol.194, pp. 3-23. DOI: 10.1016/S00092541(02)00268-1

9. Duan Z., Møller N., Weare, J. H. A general equation of state for supercritical fluid mixtures and molecular dynamics simulation of mixture PVTX properties. Geochim. Cosmochim. Acta, 1996, vol. 60, pp. 1209-1216. DOI: 10.1016/0016-7037(96)00004-X

10. Holland T., Powell R. Thermodynamics of order-disorder in minerals: II. Symmetric formalism applied to solid solutions. American Mineralogist, 1996, vol. 81(11-12), pp. 1425-1437. DOI: $10.2138 / \mathrm{am}-1996-11-1215$
11. Holland T. J. B., Powell R. An improved and extended internally consistent thermodynamic dataset for phases of petrological interest, involving a new equation of state for solids. Journal of Metamorphic Geology, 2011, vol. 29(3), pp. 333-383. DOI: 10.1111/j.15251314.2010.00923.x

12. Connolly J. A. Computation of phase equilibria by linear programming: a tool for geodynamic modeling and its application to subduction zone decarbonation. Earth and Planetary Science Letters, 2005, vol. 236(1-2), pp. 524-541. DOI: 10.1016/j.eps1.2005.04.033 13. White R. W., Powell R., Holland T. J. B., Johnson T. E., Green E. C. R. New mineral activity-composition relations for thermodynamic calculations in metapelitic systems. Journal of Metamorphic Geology, 2014a, vol. 32(3), pp. 261-286. DOI: 10.1111/jmg.12071 14. Fuhrman M. L., Lindsley, D. H. Feldspar minerals. Amer Miner, 1988, vol. 73, pp. 201-215. DOI: 10.1007/978-3-642-72594-4 9 15. White R. W., Powell R., Holland T. J. B., Worley B. A. The effect of $\mathrm{TiO} 2$ and $\mathrm{Fe} 2 \mathrm{O} 3$ on metapelitic assemblages at greenschist and amphibolite facies conditions: mineral equilibria calculations in the system K2O-FeO-MgO-A12O3-SiO2-H2O-TiO2-Fe2O3. Journal of Metamorphic Geology, 2000, vol. 18(5), pp. 497-512. DOI: 10.1046/j.1525-1314.2000.00269.x

16. White R. W., Powell R., Johnson T. E. The effect of Mn on mineral stability in metapelites revisited: new $\mathrm{a}-\mathrm{x}$ relations for manganese-bearing minerals. Journal of Metamorphic Geology, 2014b, vol. 32(8), pp. 809-828. DOI: 10.1111/jmg. 12095

17. Berman R. G. WinTWQ (version 2.3): A software package for performing internally-consistent thermobarometric calculations. $G e$ ological Survey of Canada Open File 5462. 2007.

18. Blundy J. D., Holland T. J. B. Calcic amphibole equilibria and a new amphibole-plagioclase geothermometer. Contribution to Mineralogy and Petrology, 1990, vol. 104, pp. 208-224.

19. Safonov O. G., Reutsky V. N., Golunova M. A., Butvina V. G., Yapaskurt V. O., Varlamov D. A. Razlichnye istochniki ugleroda vo fluidah granitoidov $v$ granulitovyh kompleksah. [Various sources of carbon in granitoid fluids in granulite complexes]. XXI Simpozium po geohimii ixotopov imeni akademika A.P. Vinogradova. [XXI Symposium on the Geochemistry of Isotopes named after Academician A. P. Vinogradov]. Moscow, Russia, November 15-17, 2016. (In Russ.) 20. Safonov O. G., Reutsky V. N., Golunova M. A., Butvina V. G., Yapaskurt V. O., Varlamov D. A., Shcherbakov V. D., van Rinnen D. D. Izotopnye harakteristiki ugleroda kak indicator istochnika vysokotemperaturnyh granitoidov $v$ granulitovyh kompleksah. [Isotopic characteristics of carbon as an indicator of a source of hightemperature granitoids in granulite complexes]. Geodinamika rannego Dokembriya: shodstvo I razlichiya s Fanerozoyem. [Geodynamics of the Early Precambrian: similarities and differences with the Phanerozoic]. Petrozavodsk, May 29-31, 2017. pp. 216-218. (In Russ.)
Бутвина Валентина Григорьевна - к. г.-м. н, с. н. с., Институт экспериментальной минералогии им. академика Д. С. Коржинского РАН, Черноголовка, Московская обл., Российская Федерация; E-mail: butvina@iem.ac.ru; ORCID http://orcid.org/0000-0002-1114-4646

Сафонов Олег Геннадьевич - д. г.-м. н., профессор, директор, Институт экспериментальной минералогии им. академика Д.С. Коржинского РАН, Черноголовка, Московская обл., Российская Федерация; E-mail: oleg@iem.ac.ru; ORCID http://orcid.org/0000-0002-8163-4667

Голунова Мария Алексеевна - к. г.-м. н, с. н. с., Институт экспериментальной минералогии им. академика Д.С. Коржинского РАН, Черноголовка, Московская обл., Российская Федерация; E-mail: nov@iem.ac.ru;

ORCID http://orcid.org/0000-0002-7251-1876

Авторы прочитали и одобрили окончательный вариант рукописи.
Valentina G. Butvina - PhD in Geol-Min., senior research fellow, D.S. Korzhinskii Institute of Experimental Mineralogy Russian Academy of Sciences, Chernogolovka, Moscow region, Russia Federation; E-mail: butvina@iem.ac.ru; ORCID http://orcid.org/0000-0002-1114-4646

Oleg G. Safonov - PhD, Dr.habil. in Geol-Min., Professor, Director, D.S. Korzhinskii Institute of Experimental Mineralogy Russian Academy of Sciences, Chernogolovka, Moscow region, Russia Federation; E-mail: oleg@iem.ac.ru; ORCID http://orcid.org/0000-0002-8163-4667

Maria A. Golunova - PhD in Geol-Min., senior research fellow, D.S. Korzhinskii Institute of Experimental Mineralogy Russian Academy of Sciences, Chernogolovka, Moscow region, Russia Federation; E-mail: nov@iem.ac.ru; ORCID http://orcid.org/0000-0002-7251-1876

All authors have read and approved the final manuscript. 